\title{
REMOÇÃO DO CORANTE AMARANTO (C.I. 16.185) POR BIOMASSA DE LEVEDURAS DO GÊNERO CANDIDA ATRAVÉS DE BIOSORÇÃO
}

\author{
ADSORPTION OF ACID DYE AMARANTH FOR THE \\ YEASTS OF THE GENUS CANDIDA IN AQUEOUS MEANS
}

\section{AKEMI TERAMOTO DE CAMARGO ${ }^{1}$ CARLOS RENATO CORSO}

1 Professora do Departamento de Biologia Geral da Universidade Estadual de Ponta Grossa 2 Professor do Departamento de Bioquímica e Microbiologia da Universidade Estadual Paulista “Júlio de Mesquita Filho”, campus de Rio Claro

\section{RESUMO}

Testou-se a capacidade de adsorção de corante ácido Amaranto (C.I. 16.185) pelas leveduras do gênero Candida em meios aquosos, em diferentes condições de pH (1,5 a 6,5), por 150 minutos de interação, a $30^{\circ} \mathrm{C}$. Além deste estudo, foram realizadas as análises de diâmetro celular médio das leveduras através de contador multicanal de partículas e a influência do fator superfície no processo de remoção do corante. Os resultados demonstraram que as leveduras C. catenulata e C. kefyr, apresentaram maior afinidade com o corante, que $C$. rugosa e $C$. utilis, removendo acima de $90 \%$ do meio. A superfície celular das leveduras parece não influir no índice de remoção, sendo que este, provavelmente é afetado pelas características específicas de cada espécie de levedura testada. Existe possibilidade do uso de leveduras do gênero Candida testadas no tratamento de resíduos líquidos contendo PUBLICATIO UEPG - Biological and Health Sciences, 8 (1):75-85, 2002. 
corantes em reatores biológicos.

Palavras-chave: adsorção; biosorção; corante; leveduras; tratamento biológico

\section{Introdução}

As águas residuárias de indústrias fabricantes ou processadoras de corantes constitui-se, ainda, num fator de constante preocupação, quando seus resíduos são lançados em recursos naturais “in natura”, sem qualquer tipo de tratamento, devido ao seu potencial de toxicidade, não só à biota aquática, como também ao homem que se utiliza dessas águas, após algum tratamento realizado pelas empresas regionais de saneamento básico. Dessa forma, as pesquisas na área que visam a elaboração de métodos eficazes e econômicos para a retirada destes compostos dos rios de forma integral tem caráter prioritário, já que os métodos convencionais utilizados atualmente concorrem para a degradação dos mesmos. Este fato resulta na formação de subprodutos desconhecidos e até mesmo potencialmente carcinogênicos e mutagênicos, como no caso das aminas aromáticas e compostos fenólicos (GREENLE et al., 1985; GREGORY, 1986; TIEDGE et al., 1986, entre outros).

O maior inconveniente do despejo indiscriminado destes resíduos, consiste no fato de que estes geralmente contêm substâncias orgânicas e inorgânicas de difícil degradação, mesmo a longo prazo (ANLIKER et al., 1981; BROWN, HAMBURGER, 1987). A literatura tem demonstrado que os corantes, em geral, são biodegradados de forma muito lenta, sendo mais eficiente em condições anaeróbias (PORTER \& SNIDER, 1976; RADDING et al., 1978; PAGGA \& BROWN, 1986). Além deste aspecto de alta recalcitrância, deve-se levar em consideração o seu alto potencial para a bioacumulação nas cadeias alimentares (TONOGAI et al., 1980; TIEDGE et al., 1986).

A cor é o mais óbvio indicador de poluição da água. A descarga de efluentes coloridos, além de ser tóxica, é prejudicial à natureza estética de correntes receptoras naturais. Além disso, a cor interfere com a transmissão de luz solar dentro da corrente e, portanto, reduz a atividade fotossintética. A oxidação biológica desse material consome o oxigênio dissolvido existente e, em conseqüência, causa o aumento da demanda bioquímica de oxigênio (D.B.O.). Ocorre então, a predominância da vida anaeróbia, 
que realiza os processos fermentativos em ausência de oxigênio, liberando substâncias de odor desagradável como sulfetos e mercaptanas, característicos de ambientes sépticos (SILVEIRA, SANTANNA, 1990 in MARGULIS, 1990).

Os efluentes de muitas instalações industriais (têxteis, alimentícias, farmacêuticas, de curtume, cosméticas, de papéis, de plásticos, madeiras, tintas, etc.) contêm grandes concentrações de compostos coloridos. Devido ao seu alto grau de coloração, estes efluentes são facilmente visíveis ao penetrar em corpos d'água. A indústria têxtil destaca-se pelo seu grande consumo de água, em todas as etapas de lavagem e tingimento de tecidos naturais e sintéticos, mas, inclusive, pelas complexas substâncias poluentes que contêm suas águas residuárias. Muitos corantes contêm impurezas na forma de metais pesados provenientes de produtos intermediários empregados em sua fabricação (DURIG, 1976).

Esse tipo de produção em escala industrial gera resíduos, cuja recuperação é, na maioria das vezes indesejável, por causar ônus para a empresa na construção de instalações de tratamento de efluentes. Porém, atualmente, os resíduos gerados de processos de coloração são de grande interesse ambiental, devido ao seu potencial de risco à saúde humana, quando da ineficiência no tratamento utilizado (STRAUB et al., 1993).

Portanto, se essa recuperação for parcial ou envolver um acompanhamento inadequado, poderá deixar escapar substâncias que, apesar de incolores, são mais tóxicas que os corantes iniciais, dificilmente detectáveis por métodos convencionais, exigindo para isso, métodos cada vez mais sofisticados e onerosos.

A remoção de cor no perfil econômico atual, permanece um desafio importante. Inúmeros trabalhos tem sido realizados sobre a remoção de cor de efluentes têxteis através de coagulação química, oxidação química, osmose reversa, cloração, ozonólise, técnicas biológicas e por adsorção. A adsorção parece oferecer as melhores perspectivas sobre as demais técnicas de tratamento (McKAY, 1978). O carvão ativado é o mais popular adsorvente e tem sido usado com grande sucesso, apesar de ser muito oneroso. Conseqüentemente, novos materiais estão sendo estudados: sílica-gel, alumina, sais férricos, turfa, entre outros.

Levando-se em consideração os aspectos abordados anteriormente, muitos pesquisadores reforçam a necessidade do aprimoramento de novas técnicas de tratamento, incluindo entre elas a absorção e ou adsorção (biosorção) através de tratamento microbiológico, usando para tanto, as propriedades das superfícies biológicas de microrganismos como leveduPUBLICATIO UEPG - Biological and Health Sciences, 8 (1):75-85, 2002. 
ras, fungos e bactérias aeróbias e anaeróbias como material "biosorvente", adsorvente ou absorvente.

A maior parte da literatura referenciada atualmente, no tocante aos trabalhos sobre os aspectos biosortivos são relacionados a diferentes tipos de metais (cádmio, zinco, chumbo, entre outros) e microrganismos (bactérias, algas e fungos) como estudados por Wainwright et al.,1996; Niu et al., 1993; Angelis et al., 1981; Corso et al., 1981; Holan et al., 1993; Marcanti Contato, 1995, entre outros.

Assim, na tentativa de eliminar os corantes em sua forma integral, sem realizar sua quebra redutiva e aproveitando-se da facilidade de interação dos microrganismos (biosorção) com alguns corantes (CORSO et al., 1981; TERAMOTO DE CAMARGO, 1987; TERAMOTO DE CAMARGO, 1996), foram realizados testes em escala de laboratório. A possibilidade de remover corantes azóicos por biomassa de leveduras foi examinado, como forma de tratamento microbiológico de corantes e seus resíduos em meios aquosos.

\section{Metodologia}

As leveduras do gênero Candida: C. catenulata, C. utilis, C. kefyr e C. rugosa foram mantidas em ágar- malte a $\%$ (LODDER, 1971), conforme descrito na Tabela I, e transferidas a tubos-teste (pré-inóculo) contendo meio basal para leveduras (SAVOY, 1981), conforme descrito na Tabela 2, e agitados para homogeneizar a suspensão. Em seguida, os tubos foram incubados em estufa a $28^{\circ} \mathrm{C}$ por 24 horas. Após, o pré-cultivo foi transferido a Erlenmeyers de $250 \mathrm{~mL}$ contendo $100 \mathrm{~mL}$ de meio basal e incubados sob agitação a $24 \pm 2^{\circ} \mathrm{C}$ por 24 horas em uma mesa rotatória ("shaker”) de 250 r.p.m. Em seguida, $25 \mathrm{~mL}$ do cultivo foi transferido para Erlenmeyers de $500 \mathrm{~mL}$ contendo $200 \mathrm{~mL}$ de meio basal e incubados da mesma forma anterior por 48 horas. Na seqüência, o conteúdo dos frascos foi centrifugado a 7.000 r.p.m. por 10 minutos para separar as células do sobrenadante. A biomassa foi lavada com água esterilizada e centrifugada processo este repetido por três vezes. As células lavadas foram resuspensas em água estéril (suspensão-estoque de células para os testes de adsorção).

Suspensões de células (3,0 g de peso seco de biomassa por litro) foram colocadas em contato com $30 \mathrm{mg} . \mathrm{L}^{-1}$ do corante Amaranto C.I. 16.185 (vermelho ácido 27) em tubos a $30^{\circ} \mathrm{C}$ em diferentes valores de $\mathrm{pH}$ entre 1,5 PUBLICATIO UEPG - Ciências Biológicas e da Saúde, 8 (1): 75-85, 2002. 
e 6,5. Amostras foram coletadas após 30, 60, 90, 120 e 150 minutos de contato, e centrifugadas (7000 r.p.m. por 10 minutos) para obter o corante remanescente, que foi analisado quantitativamente por espectrofotometria no visível a 522,5 nm (comprimento de onda de máxima absorção do corante). Além destas análises, foram realizadas as determinações de diâmetro celular médio da suspensão-estoque de leveduras usadas nos testes de interação, através do contador multi-canal de partículas (Coulter Counter Model TA II) com NaCl 1\% e tubos com 50 m de diâmetro. A contagem direta de células foi realizada em microscópio ótico e expresso em número de células por grama de suspensão de leveduras. De posse desses dados, foi possível determinar após apropriadas conversões, a superfície celular expressa em metro quadrado por grama $\left(\mathrm{m}^{2}(/ \mathrm{g})\right.$.

Tabela 1 - Meio de preservação de culturas de leveduras: ágar-malte 2\% (LODDER, 1971):

\begin{tabular}{|c|c|}
\hline 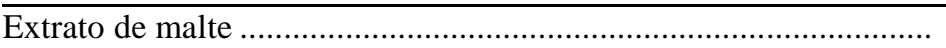 & $2,0 \mathrm{~g}$ \\
\hline Agar-agar ... & $1,8 \mathrm{~g}$ \\
\hline Água destilada..... & $100 \mathrm{~mL}$ \\
\hline
\end{tabular}

Tabela 2 - Meio basal para leveduras (SAVOY, 1981):

\begin{tabular}{|c|c|}
\hline Sulfato de Amônio & $3,0 \mathrm{~g}$ \\
\hline Sulfato de Magnésio Hepta Hidratado ........ & $0,25 \mathrm{~g}$ \\
\hline Cloreto de Cálcio Hepta Hidratado .............. & $0,25 \mathrm{~g}$ \\
\hline Ácido Bórico .......................... & $0,001 \mathrm{~g}$ \\
\hline Sulfato de Zinco ..................... & $0,001 \mathrm{~g}$ \\
\hline 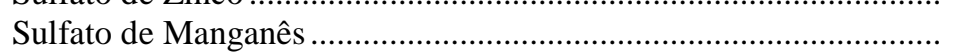 & $0,001 \mathrm{~g}$ \\
\hline Cloreto Férrico ....................... & $0,001 \mathrm{~g}$ \\
\hline Sulfato de Cobre.................... & $0,0001 \mathrm{~g}$ \\
\hline Iodeto de Potássio . & $0,0001 \mathrm{~g}$ \\
\hline Ácido Aspártico ........................... & $0,1 \mathrm{~g}$ \\
\hline 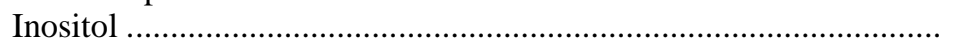 & $0,05 \mathrm{~g}$ \\
\hline$\beta$ - Alanina.......................... & $20,0 \mu \mathrm{g}$ \\
\hline Cloridrato de Piridoxina.. & $20,0 \mu \mathrm{g}$ \\
\hline Cloridrato de Tiamina ........ & $20,0 \mu \mathrm{g}$ \\
\hline 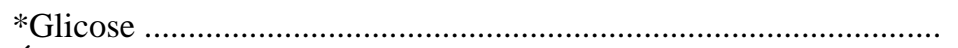 & $20,0 \mathrm{~g}$ \\
\hline $\begin{array}{l}\text { Água Destilada q.s.p } \\
\mathrm{pH}=6,0\end{array}$ & $1000 \mathrm{~mL}$ \\
\hline
\end{tabular}

* A glicose foi preparada e esterilizada em frasco separado dos demais componentes do meio e adicionada a este, no momento de se inocular as devidas culturas. 


\section{Resultados}

Tabela 3 - Porcentagem de remoção do Amaranto em diferentes valores de pH por leveduras do gênero Candida, no tempo de equilíbrio de 120 minutos; concentração de corante de $30 \mathrm{mg} \cdot \mathrm{mL}^{-1}$ e concentração celular de 3,0 g.L ${ }^{-1}$.

\begin{tabular}{|l|c|c|c|c|c|c|}
\hline & & & $\mathrm{pH}$ & & & \\
\hline & 1,5 & 2,5 & 3,5 & 4,5 & 5,5 & 6,5 \\
\hline ESPÉCIE & & & & & & \\
\hline C. catenulata & 93,7 & 88,8 & 66,0 & 20,1 & 5,9 & 1,7 \\
\hline C. kefyr & 92,1 & 85,6 & 13,3 & 5,6 & 1,7 & 1,7 \\
\hline C. utilis & 15,1 & 11.6 & 7,4 & 1,8 & 2,6 & 3,3 \\
\hline C. rugosa & 14,2 & 12,3 & 7,5 & 3,0 & 3,1 & 3,8 \\
\hline
\end{tabular}

Tabela 4 - Determinação de superfície celular de leveduras do gênero Candida através do diâmetro médio de células, obtida pela contagem eletrônica de partículas e número de células na suspensão celular.

\begin{tabular}{|l|c|c|c|}
\hline \multicolumn{1}{|c|}{ ESPÉCIE } & Diâmetro médio & $\mathrm{N}^{0}$ de células & Superfície celular \\
\hline C. catenulata & $(\mu)$ & $\left(1,0\right.$ g. $\left.\mathrm{L}^{-1}\right)$ & $\left(\mathrm{m}^{2} / \mathrm{g}\right)$ \\
\hline C. kefyr & 3,53 & $337 \times 10^{9}$ & 13,19 \\
\hline C. utilis & 5,96 & $82 \times 10^{9}$ & 9,15 \\
\hline C. rugosa & 7,15 & $181 \times 10^{9}$ & 29,01 \\
\hline
\end{tabular}

Coeficiente de Correlação: Amaranto removido X Superfície celular: $\mathrm{R}=0,500$ 

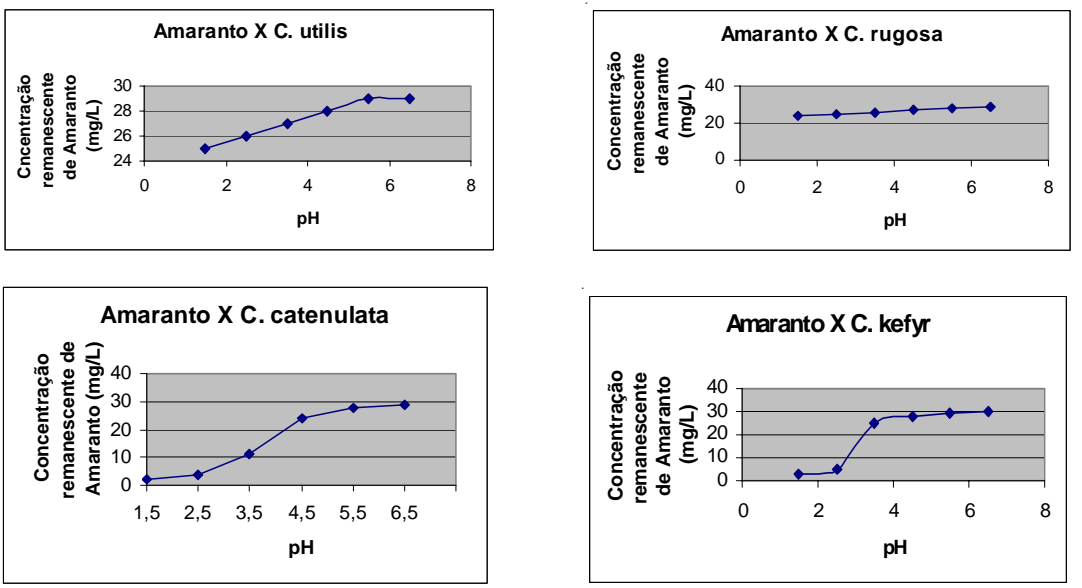

Figura 1 - Estudo da biosorção do corante ácido Amaranto C.I. 16.185 por biomassa celular de leveduras do gênero Candida, obtidos nos valores de pH entre 1,5 e 6,5, à temperatura de $30^{\circ} \mathrm{C}$; concentração inicial de corante de $30 \mathrm{mg} /$

$\mathrm{L}$; biomassa de 3,0 g/L; tempo de contato de 120 minutos.

\section{Discussão}

Os resultados obtidos mostraram que o Amaranto foi gradualmente removido pelas leveduras quando os valores de $\mathrm{pH}$ decresceram. Com respeito à estabilização do tempo de equilíbrio dos testes, observou-se que após 120 minutos não houve nenhuma expressiva remoção de cor. Um exame da Tabela 3 mostra que C. catenulata e $C$. kefyr promoveu a remoção do Amaranto atingindo níveis superiores a 90\%. Enquanto isso, $C$. utilis e $C$. rugosa demonstraram ter baixa afinidade pelo corante, mesmo em valores de $\mathrm{pH}$ mais ácidos. Uma análise da Figura I, na qual se apresenta o estudo de biosorção do corante Amaranto pelas células de Candida (3,0 g/L), em sistemas de $\mathrm{pH}$ entre 1,5 e 6,5, à temperatura de $30^{\circ} \mathrm{C}$ e concentração inicial de corante de $30 \mathrm{mg} / \mathrm{mL}$, em contato por 120 minutos de interação, mostra as curvas de remoção do corante. Observa-se a confirmação dos dados observados na Tabela 3, que C. catenulata e C. kefyr apresentaram maior afinidade na remoção do Amaranto do que C. rugosa e C. utilis. 
Observando-se a Tabela 4, verifica-se que o diâmetro médio das células de Candida é muito variável. Então, C. catenulata apresentou cerca de metade do diâmetro médio das células de $C$. utilis. Pela análise do número de células e superfície celular, $C$. utilis apresentou maior área superficial, porém, comparando-se à Tabela 3, observa-se que não foi esta a espécie que apresentou maior afinidade com o Amaranto. O melhor desempenho observado foi da espécie $C$. catenulata, seguida de $C$. kefyr, que também apresentou pequena área superficial. Pela análise dos valores de correlação linear dos dados de Amaranto removido X superfície celular, observa-se que não houve aparente correlação dos seus dados $(\mathrm{R}=0,500)$. Conseqüentemente, isto sugere que o processo de biosorção não depende superfície celular, não havendo relação entre superfície disponível de células e quantidade de corante adsorvido. Isto reforça a idéia de que, em um simples gênero, a capacidade de adsorção está relacionada às características da membrana celular de cada espécie em questão. Isto também sugere a possibilidade do uso de leveduras do gênero Candida em projetos de tratamento microbiológico de corantes ou de seus resíduos, como uma forma alternativa para seu uso em bio-reatores para a remoção dos mesmos.

\section{Conclusões}

- O Amaranto apresenta espectros estáveis com a variação do pH (1,5 a 6,5) no comprimento de onda de máxima absorção (522,5 nm), comportando-se de uma forma pH-estável.

- Para o Amaranto, com o abaixamento do pH, há uma gradativa remoção do corante pelas leveduras testadas.

- As diferentes espécies de leveduras do gênero Candida removem o corante estudado de uma forma distinta.

- As espécies C. catenulata e $C$. kefyr apresentam grande afinidade para a remoção do Amaranto, enquanto que $C$. utilis e C. rugosa apresentam baixa afinidade com o mesmo.

- A partir de 90 minutos de contato corante-biomassa, existe uma estabilização na remoção do Amaranto pelas leveduras testadas, portanto não havendo necessidade de maior tempo de interação.

PUBLICATIO UEPG - Ciências Biológicas e da Saúde, 8 (1): 75-85, 2002. 
- Os diâmetros celulares médios das leveduras, nas condições testadas são diferentes.

- Nos estudos de interação do corante Amaranto e as leveduras do gênero, verificou-se que não existe correlação entre superfície celular e capacidade adsortiva das leveduras.

- Num mesmo gênero, a capacidade de remoção do corante está relacionada com as características intrínsecas da membrana celular de cada espécie estudada.

- Existe possibilidade do uso de leveduras do gênero Candida numa das etapas de tratamento de efluentes contendo corantes ou resíduos de corantes em reatores biológicos.

Recebido para publicação em 4/01.

Recebido para publicação em 11/02.

\begin{abstract}
The capacity of adsorption of acid dye Amaranth was tested (C.I. 16.185) for the yeasts of the genus Candida in aqueous means, in different $\mathrm{pH}$ conditions (1,5 to 6,5), for 150 minutes of interaction, to $30^{\circ} \mathrm{C}$. Besides this study, the analyses of medium cellular diameter of the yeasts were accomplished through multichannel counter of particles and the influence of the factor surface in the process of removal of the color. The results demonstrated that the yeasts C. catenulata e C. kefyr, presented larger likeness with the color, that $C$. rugosa and $C$. utilis, removing above $90 \%$ of the middle. The cellular surface of the yeasts seems not to influence in the removal index, and this, it is probably affected by the specific characteristics of each species of tested yeast. Have possibility of the use of yeasts of the genus Candida tested in the treatment of liquid residues containing dyes in biological reactors.
\end{abstract}

Key words: adsorption; biosorption; dyes; yeasts; biological treatment

Endereço para contato: akemitc@uepg.br

PUBLICATIO UEPG - Biological and Health Sciences, 8 (1):75-85, 2002. 
1 ANGELIS, D.F. et al. Corantes do tipo azo removidos por meio biológico. In: II Seminário Regional de Ecologia (Anais) UFSCar, São Carlos, São Paulo, p. 287303, 1981.

2 ANLIKER, R.; CLARKE, E. A . MOSER, P. Use of partition coefficient as an indicator of bioaccumulation tendency of dyestuffs in fish. Chemosphere, v. 3, p. 263-74, 1981.

3 BROWN, D.; HAMBURGER, B. The degradation of dyestuffs: part III. Investigations of their ultimate degradability. Chemosphere, v.16, n. 7, p. 153953, 1987.

4 CORSO, C.R. et al. Interaction between diazo dye Vermelho Reanil P8B and Neurospora crassa, strain 74-A. European Journal of Applied Microbiology and Biotechnology, v. 13, p. 64-6, 1981.

5 DURIG, G. Ecological aspects of water usage in the textile industry. Rev. Prog. Coloration, v. 7, p. 70-80, 1976.

6 GREENLE, W. F.et al. Toxicity of chlorinated aomatic compounds in animals and humans: in vitro approaches to toxic mechanisms and risck assessment. Environmental Health Perspectives, v. 60, p. 69-76, 1985.

7 GREGORY, P. Azo dyes: structure-carcinogenicity relantionships. Dyes and Pigments, n. 7, p.45-56, 1986.

8 HOLAN, Z.R.; VOLESKY, B.; PRASETYO, I. Biosorption of cadmium by biomass of marine algae. Biotechnology and Bioengineering, v. 41, p. 819-25, 1993.

9 MARCANTI-CONTATO, I. Emprego de Aspergillus niger paramorfogênico para a avaliação do grau de interferência dos aditivos químicos na biosorção de corantes têxteis de efluentes industriais. Rio Claro, UNESP, 1995, 173 p. Tese (Doutorado em Biologia Vegetal) I. Instituto de Biociências, UNESP.

10 SILVEIRA, S. S. B.; SANT’ANNA, F. S. P. Poluição Hídrica. In: MARGULIS, S. (Ed.). Meio Ambiente: aspectos técnicos e econômicos. Brasília: PNDU/IPEA, p. 57-84, 1990.

11 McKAY, G.; OTTERBURN, M.S.; SWEENEY, A. G. The removal of colour from effluent using various adsorbents: some preliminary economic considerations. Journal of Society Dyes Colourists, v. 94, n. 4, p. 247-68, 1978.

12 NIU, H. et al. Removal of lead from aqueous solutions by Penicillium biomass. 
Biotechnology and Bioengineering, v. 42, p. 785-87, 1993.

13 PAGGA, U.; BROWN, D. The degradation of dyestuffs. II. Behaviuor of dyestuff in aerobic biodegradation tests. Chemosphere, v. 15, n. 4, p. 479-91, 1986.

14 PORTER, J. J.; SNIDER, E. H. Long-term biodegradability of textile chemical. Journal of Water Pollution Control Federation, v. 48, n. 9, p. 2198-210, 1976.

15 RADDING, S.B. et al. Assessment of potencial toxic releases from leather industry dyeing operations. EPA-600/2-78-215. Cincinnati, Ohio, 65 p., 1978.

16 SAVOY, N. M. M. Ação da difenilamina na obtenção de lipídeos em Candida utilis, Candida solani e Torula utilis. Rio Claro, 1981. 125 p. Dissertação (Mestrado). Universidade Estadual Paulista "Júlio de Mesquita Filho".

17 STRAUB, R.F.; VOYSKNER, R.D.; KEEVER, J. T. Determination of amine originating from azo dyes by hydrogen-palladium reduction combined with gas chromatography mass spectrometry. Anal. Chem., n. 65, p. 2131-36, 1993.

18 TERAMOTO DE CAMARGO, A. Remoção de corantes azóicos Amaranto C.I. 16.185 (Vermelho Ácido 27) e Crisoidina C.I. 11.270 (Laranja Básico 2) em soluções aquosas por leveduras do gênero Candida. Rio Claro, 1987. 122 p. Dissertação (Mestrado). Universidade Estadual Paulista “Júlio de Mesquita Filho”.

19

Estudo de otimização do processo de biosorção de corantes reativos por leveduras do gênero Candida. Rio Claro, 1996. 127 p. Tese (Doutorado). Universidade Estadual Paulista "Júlio de Mesquita Filho".

20 TIEDGE, H.; NAGEL, R.; URICH, K. Effect of substituted phenols on transaminase activity in the fish Leuciscus melanotus, L. Bulletin of Environmental Contamination and Toxicology, n. 36, p. 176-80, 1986.

21 TONOGAI, Y. et al. Studies on the toxicity of coal-tar dyes III. Reason of acute toxicity to fish caused by coal-tar dyes and their industrial effluents. Journal of Toxicological Sciences, n. 5, p. 23-33, 1980.

22 WAINWRIGHT, A. B.; SUSAN, J.; JONG, P. M. Adsorption of insoluble compounds by mycelium of the fungus Mucor flavus. Enzyme Microbiology Technology, n. 8, p. 597-600, oct.,1996. 